\title{
Influence of Processes on the Properties of Nano-fibrous Fibers of the Electro-spinning Polyamide- 6
}

\author{
Mohamed Moussa ${ }^{1, ~ *, ~ F a b i e n ~ S a l a u ̈ n ~}{ }^{2}$, Neda Shah Hossein ${ }^{2}$, Rajerison Wilson ${ }^{1}$ \\ ${ }^{1}$ Department of Industrial Process and Ecology, Faculty of Sciences, University of Antananarivo, Antananarivo, Madagascar \\ ${ }^{2}$ The National School of Arts and Textile Industries, Roubaix, France
}

Email address:

moussa.mohamed@ac-versailles.fr (M. Moussa)

${ }^{*}$ Corresponding author

\section{To cite this article:}

Mohamed Moussa, Fabien Salaün, Neda Shah Hossein, Rajerison Wilson. Influence of Processes on the Properties of Nano-fibrous Fibers of the Electro-spinning Polyamide-6. American Journal of Polymer Science and Technology. Vol. 7, No. 1, 2021, pp. 10-15.

doi: 10.11648/j.ajpst.20210701.12

Received: December 29, 2020; Accepted: January 16, 2021; Published: February 2, 2021

\begin{abstract}
This study focuses on the influence of electrospinning processes on the properties of electrospun fibres. We have optimised the parameters: distance, voltage, concentration of electrospinning to analyse the influence of these parameters on the properties, in particular the structure and morphology of the nano-fibres. The mass of the required polyamide was measured using an analytical balance and dissolved in formic acid to obtain a homogeneous mixture. The solution was stirred for 24 hours and then cooled and inserted into the syringe to be electro-threaded. The concentration of the solution played a decisive role during the spinning process and influenced in particular the determination of the diameter but also the morphology of the nanofibres. A concentration of 15\% PA-6 and a low viscosity solution of $266 \mathrm{mPa}$ allowed us to obtain higher quality fibres. The results obtained by the SEM show that the increase in the electric field causes the fibre diameter to increase from $170 \mathrm{~nm}$ to $234 \mathrm{~nm}$. The structures, nano-fibre morphologies and thermal properties of PA-6 have been characterised using scanning electron microscopy (SEM), differential scanning calorimeter (DSC) and thermogravimetric analysis (TGA). Defect-free fibres with extremely small diameters and a large specific surface area were produced. Which we will use to manufacture photo deformable textiles. After spinning the flawless fibres, we can continue this study in the near future by adding a fire retardant active ingredient to the polyamide solution, to improve the resistance of the fibres and their morphology.
\end{abstract}

Keywords: Electrospinning, Fibers, Experimental Design, Thermal Properties, Structure and Morphology

\section{Introduction}

Many methods have been used to prepare polymer nanofibers in recent years, such as template synthesis [1-2], phase separation [3], self-assembly [4, 5], and electrospinning [6, 7]. The latter would be the already most efficient method, and can be further improved, for the mass production of microand nano-spinning of various polymers [8]. More than sixty polymers have been processed by this method, leading to fibrous structures with diameters ranging from the micrometer to the nanometer [9]. Experimentally, an electrothreading device (Figure 1) consists of three basic parts: an injector with a metal needle installed on a pump, a metal collector and a high-voltage source.
The polymer solution is well homogenized before being introduced into the injector. Its concentration is adjusted to obtain regular fibers. This concentration must be sufficient to obtain a continuous jet of solution, ensuring the polarization of the electrospinning solution, the other electrode being fixed to the collector, usually simply grounded [10]. From a mechanical point of view, in order to ensure the electrospinning process, a high voltage $(14-20 \mathrm{kV})$ is applied in order to create a jet, electrically charged, of the polymer solution out of the needle. The charges on the surface of the solution cause a force directly opposite to the surface voltage [11-13], so as the electric field strength increases, the 
hemispherical surface of the solution at the tip of the needle becomes increasingly pointed, forming a so-called Taylor cone. When the electric force is sufficiently high in relation to the surface tension, which tends to gather the volume of the liquid, a jet of solution is expelled towards the collector. Before the polymer solution reaches the collector, the solvent evaporates significantly and continuous polymer fibers are deposited on the surface of the collector [14-16]. The control of electrospinning parameters strongly influences the results of the experiments and is critical to preserve homogeneous fiber morphology.

The main parameters are:

1) The concentration of the initial solution, i.e. the viscosity of the mixture, in order to make the fiber as continuous as possible [17].

2) The potential difference at the origin of the mixing jet

3) The distance between the needle and the collector as well as the ambient temperature, which influence the evaporation time of the solvent [18].

4) Solution flow rate

In our own experiments, these parameters will be optimized so that our nano-fibers are continuous and homogeneous in order to observe the influence of the process on the properties of polyamide- 6 fibers. On the other hand, the thermal properties of the nano-fibrous film of polyamide6 fibers will be studied.

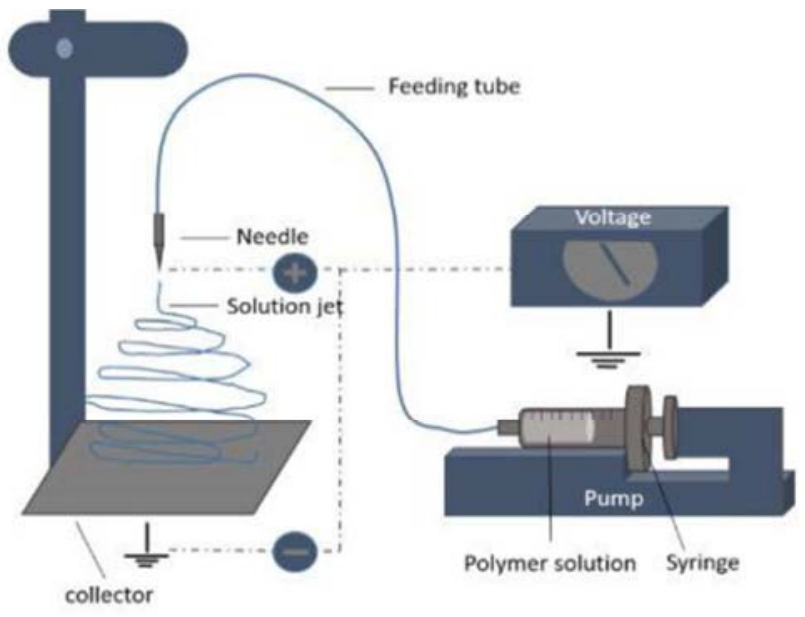

Figure 1. Vertical set up of electrospinning apparatus.

\section{Materials}

Polyamide 6 was supplied by the BASF SE (Europe) Group, formic acid (99\%, purchased from Prolabo, France) as a solvent. The parameters, which were kept constant during all experiments, are presented in Table 1.

Table 1. Parameters for electrospinning of PA-6.

\begin{tabular}{ll}
\hline Flow & Flow rate $(\mathbf{m l} / \mathbf{h}): \mathbf{0 , 1}$ \\
\hline Needle & Needle diameter $(\mathrm{G}): 55$ \\
Ambient Parameter & Temperature $\left({ }^{\circ} \mathrm{C}\right): 23$ \\
Humidity & $22 \%$ \\
Spinning time & $15 \mathrm{mn}$ \\
\hline
\end{tabular}

\section{Method}

\subsection{Electrostatic Spinning}

PA-6/AF solutions with the desired concentration were poured into a $10 \mathrm{~mL}$ syringe, typically attached to a needle. The flow rate of the solution exiting through the metal capillary of the needle was fixed and a potential difference was applied. When the high voltage is applied, a jet of the polymer solution is formed and ejected to be received by the manifold. This jet is deposited on a specimen holder in the form of a porous non-woven fabric. The formation of the membrane of reasonable volume takes between 1 and $15 \mathrm{~min}$ of tension application. After this period, the tension is removed and the quantity deposited on the collector is stored to prevent moisture.

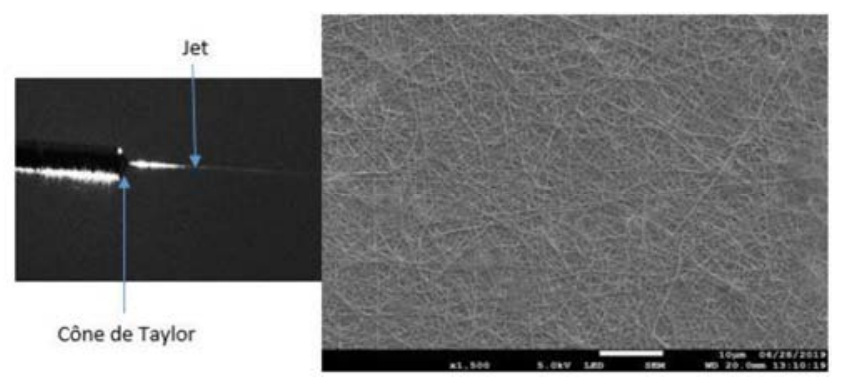

Figure 2. Presentation of Taylor cone and jet.

\subsection{Preparation of Electro-spinning Solution}

Description of polymers and solvents used the mass of polyamide required was measured with an analytical balance and dissolved in formic acid to obtain a homogeneous mixture. The concentration of the solution is 15\% PA-6 and $85 \%$ AF. The solution was stirred for 24 hours and then cooled and inserted into the syringe to be electro-threaded.

Table 2. Description of used polymers and solvents.

\begin{tabular}{ll}
\hline & Polyamide: PA-6 \\
\hline Molecular weight $(\mathrm{g} / \mathrm{mol})$ & 10,000 \\
Density $(\mathrm{g} / \mathrm{mL})$ & 1.084 \\
& Formic acid $(\mathrm{AF})$ \\
Molecular weight $(\mathrm{g} / \mathrm{mol})$ & 46,02 \\
Density $(\mathrm{g} / \mathrm{mL})$ & 1,22 \\
Purity $(\%)$ & 99 \\
\hline
\end{tabular}

\section{Results and Discussions}

\subsection{Solution Characterization Technique}

The electro-wiring process is based on the phenomenon of stretching of the charged jet. It is affected by the physicochemical properties of the PA-6/AF solution. The concentration or viscosity of the solution is the first parameter that must be optimized to obtain the desired nanofiber morphology.

This concentration, which is neither too low nor too high, gives us an ideal solution for spinning. The PA-6/AF polymer solution has a high electrical conductivity, which allows a 
high surface charge density to make the solution electro- threadable.

Table 3. Physico-chemical properties of the polymer solution.

\begin{tabular}{lllll}
\hline & Concentration $(\%)$ & Viscosity $(\mathbf{m P a})$ & Electrical conductivity $(\boldsymbol{\mu} \mathbf{S} / \mathbf{c m})$ & Surface tension $(\mathbf{m N m})$ \\
\hline PA-6/AF & 15 & 266 & 4962 & 39 \\
$\mathrm{AF}$ & 99 & 86,80 & 354,36 & 33,30 \\
\hline
\end{tabular}

\subsection{Optimization of PA-6/AF Electro-wiring}

The electro-spinning of the PA-6/AF was carried out according to a design of experiment (DoE), based on the response surface method (RSM) and shown in the table below.

Table 4. Selected Parameters with Different Levels in DOE.

\begin{tabular}{llll}
\hline Electro-spinning & Abbreviation & Units & Levels \\
\hline Concentration of solution in PA-6 & $\mathrm{C}$ & $\%$ & 15 \\
Distance & $\mathrm{D}$ & $\mathrm{cm}$ & $12,15,20$ \\
Voltage & $\mathrm{V}$ & $\mathrm{kV}$ & $14,16,18,20$ \\
\hline
\end{tabular}

Total number of experience: $3 * 6=12$

The feed rate was maintained at $0.1 \mathrm{ml} /$ hour.

The average diameters (50 fibers measured), the standard of deviation of the PA-6 electro-spinning nano-fibers produced are presented in the DoE detailed in the table above.

Table 5. DoE development for electro-spinning of PA-6.

\begin{tabular}{llllll}
\hline No & C (\%) & Distance (cm) & Voltage $(\mathbf{k V})$ & Mean.Dia $(\mathbf{n m})$ & St.Dev \\
\hline \multirow{6}{*}{} & 12 & 14 & 164 & 57 \\
& & & 16 & 210 & 35 \\
& & & 18 & 234 & 23 \\
PA-6 & \multirow{4}{*}{15} & 20 & 223 & 51 \\
& \multirow{2}{*}{15} & 14 & 212 & 28 \\
& & 16 & 164 & 48 \\
& & 18 & 123 & 39 \\
& & 20 & 234 & 58 \\
& \multirow{3}{*}{18} & 14 & 137 & 43 \\
& & 16 & 119 & 52 \\
& & 18 & 122 & 54 \\
& & 20 & 244 & 26 \\
\hline
\end{tabular}

The experiments concerning the electro-spinning of PA-6 have been finalized according to the DoE presented above. It can be seen from the table that the diameter of the PA- 6 nano-fibres in DoE varied between 119 and $244 \mathrm{~nm}$.

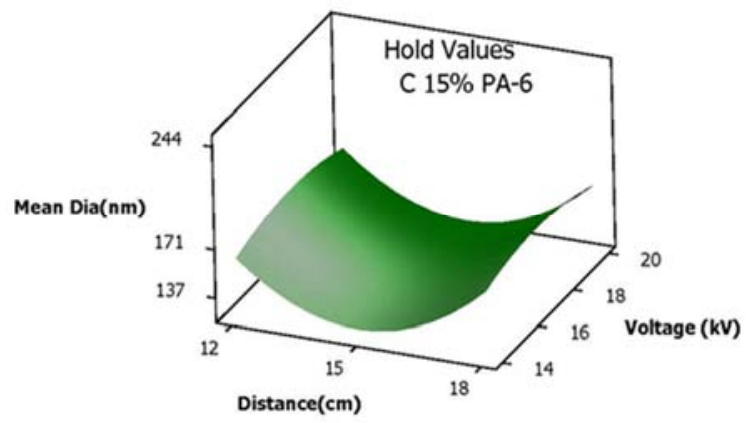

Figure 3. Surface plots for effect of inputs on PA-6 nanofiber diameter.

The combined effects of two parameters on the diameter can be visualized by this surface plot in the figure above. As shown in the surface plot above, the lowest value of the diameter is in the right corner of the graph, it is related to a distance of $15 \mathrm{~cm}$ and a voltage of $14 \mathrm{kV}$.

a. Effect of distance
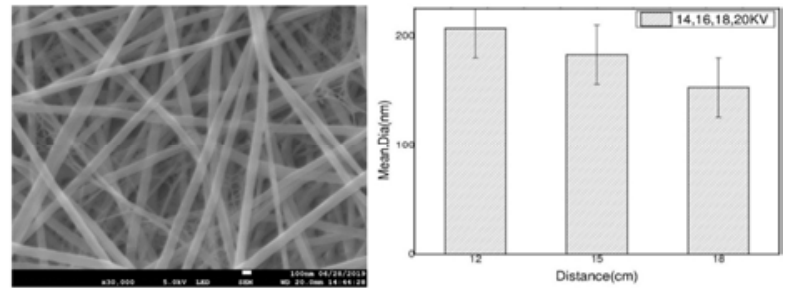

Figure 4. SEM images of an electro-spinning PA-6, voltage: $20 \mathrm{kV}$, distance: $12,15,18 \mathrm{~cm}$

The distance between the tip of the needle and the collector, also known as the working distance. Also has a significant influence on the morphology of the formed fibers. To evaluate the effect of distance on the morphology of PA-6 nano-fibers, we have carried out the electro-wiring of PA- 6 by varying the distance between 12,15 and $18 \mathrm{~cm}$. As shown in the figure above, the average fiber diameter of PA-6 increased from 202 $\mathrm{nm}(12 \mathrm{~cm})$ to $117 \mathrm{~nm}(15 \mathrm{~cm})$. Whereas at a distance of $12 \mathrm{~cm}$, the fibers obtained have a homogeneous morphology.

b. Effect of voltage
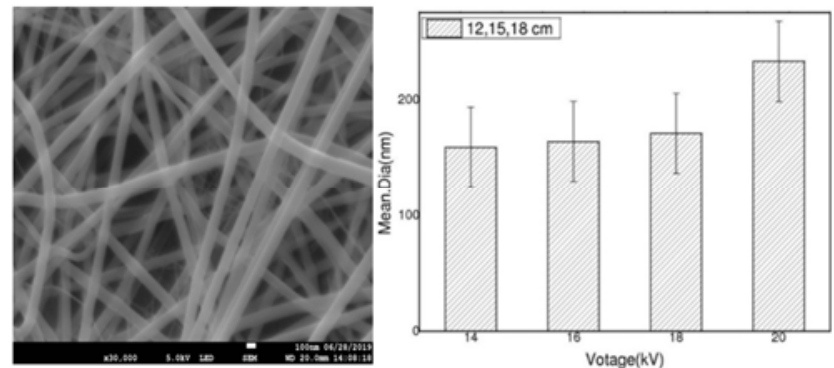

Figure 5. SEM images of an electro-spinning PA-6 solution according to different parameters: concentration: $15 \%$ PA-6, voltage: $14,16,18,20 \mathrm{kV}$, distance: $12 \mathrm{~cm}$

According to the results obtained, the nano-fibers are uniformly formed and the average diameter increases with increasing voltage. The best condition to have nano-fibers with a good and homogeneous morphology is to fix the voltage at $20 \mathrm{kV}$. In conclusion, and from the SEM photos presented above, it can be deduced that the optimal conditions for electrofiling PA-6 are: a concentration of $15 \%$ by weight PA-6, a voltage of $20 \mathrm{kV}$, a flow rate of $0.1 \mathrm{~mL} / \mathrm{h}$, a distance of $20 \mathrm{~cm}$. Using these parameters, nano-fibers with an average diameter of less than $117 \mathrm{~nm}$ can be obtained.

c. Effect of concentration 

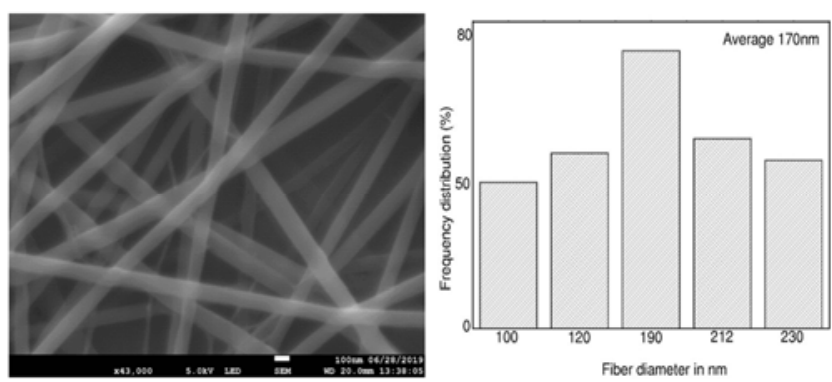

Figure 6. Influence of the 15\% PA-6 concentration: $16 \mathrm{kV}, 14 \mathrm{kV}: 12 \mathrm{~cm}$.
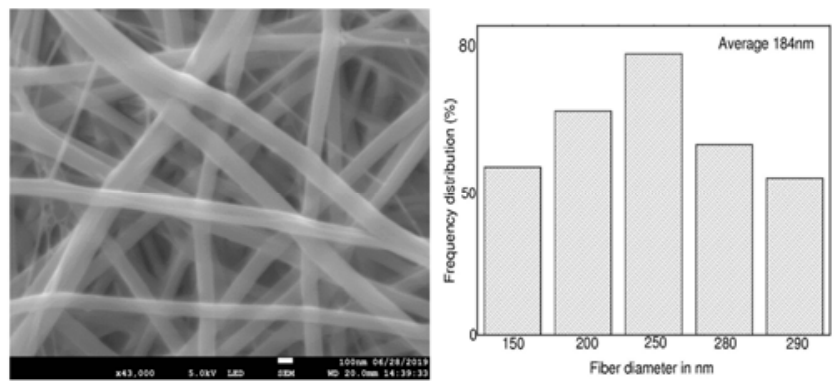

Figure 7. Influence of the 15\% PA-6 concentration: $16 \mathrm{kV}, 14 \mathrm{kV}: 15 \mathrm{~cm}$.

\section{Thermal Analysis}

\subsection{Thermogravimetric Analysis (TGA)}
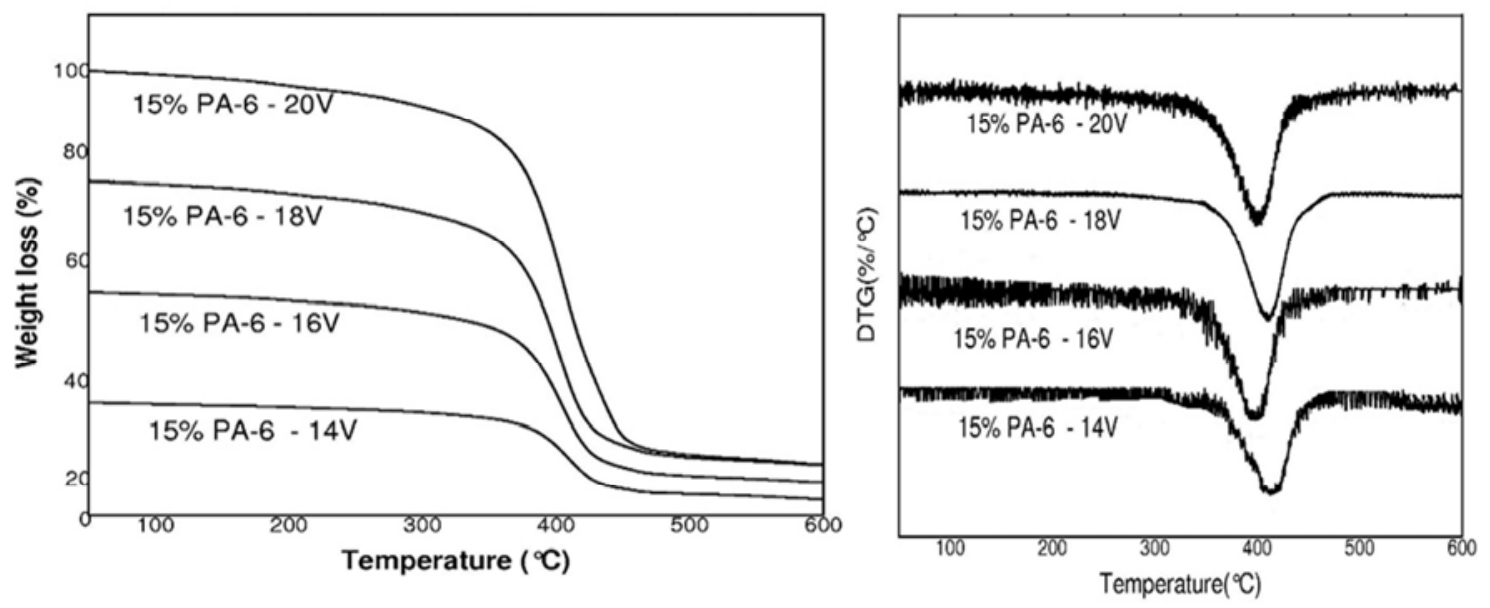

Figure 9. TG and DTG curve of PA-6 nano-fiber films.

Table 6. Thermogravimetric results of PA-6 nano-fibre films.

\begin{tabular}{|c|c|c|c|c|c|}
\hline Voltage & $\begin{array}{l}\text { Initial degradation } \\
\text { temperature }\end{array}$ & $\begin{array}{l}\text { Weight loss }(100- \\
\left.500^{\circ} \mathrm{C}\right)(\%)\end{array}$ & $\begin{array}{l}\text { Maximum degradation } \\
\text { temperature }\left({ }^{\circ} \mathrm{C}\right)\end{array}$ & $\begin{array}{l}\text { Maximum Degradation } \\
\text { rat }\left(\% /{ }^{\circ} \mathrm{C}\right)\end{array}$ & $\begin{array}{l}\text { Residue at } 700^{\circ} \mathrm{C} \\
(\%)\end{array}$ \\
\hline $14 \mathrm{~V}$ & $372,29 \pm 2,2$ & $36,70 \pm 1,6$ & $414,20 \pm 1,5$ & $2,2 \pm 0,1$ & $0,15 \pm 0,1$ \\
\hline $16 \mathrm{~V}$ & $347,51 \pm 1,1$ & $57,03 \pm 1,0$ & $396,23 \pm 1,1$ & $0,2 \pm 0,1$ & $0,11 \pm 0,2$ \\
\hline $18 \mathrm{~V}$ & $324,16 \pm 2,1$ & $77,76 \pm 0,5$ & $410,10 \pm 2,1$ & $0,7 \pm 0,01$ & $0,13 \pm 0,2$ \\
\hline $20 \mathrm{~V}$ & $292,98 \pm 1,5$ & $96,11 \pm 0,3$ & $397,30 \pm 2,6$ & $1,0 \pm 0,1$ & $0,16 \pm 0,3$ \\
\hline
\end{tabular}

The thermal behaviour of electro-spinning PA-6 nanofibres was studied using thermogravimetric analysis (TGA). The mass loss of the nano-fibres is presented in the following table. The thermogram shows a maximum initial mass loss of $96 \%$ up to an initial degradation temperature of $292^{\circ} \mathrm{C}$, which can be attributed to the removal of residual solvent or
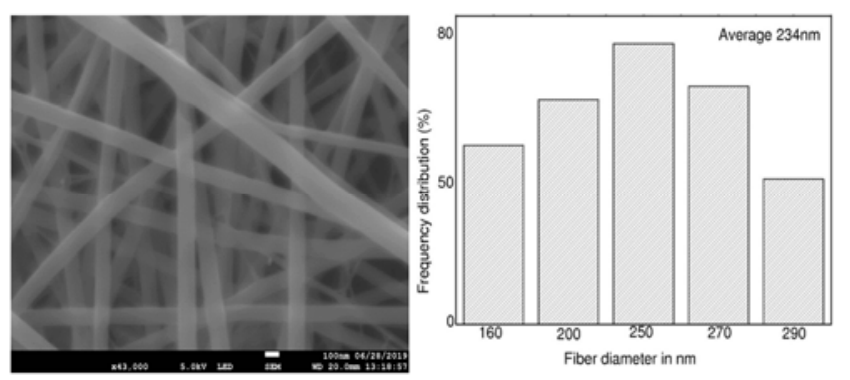

Figure 8. Influence of 15\% PA-6 concentration: $14 \mathrm{kV}: 18 \mathrm{~cm}$.

These photos illustrate the morphologies obtained as a function of concentration. Thus, in our case, the best concentration for obtaining nano-fibers with a homogeneous and equally thin fiber distribution was $15 \%$ by weight of PA- 6 . The figure above indicates that there is a slight increase in the diameter of the average fiber, from $170 \mathrm{~nm}$ to $234 \mathrm{~nm}$, with a decrease in the applied electric field. A considerable amount of fine fibers with diameters less than $170 \mathrm{~nm}$ was then observed with a narrow diameter distribution and a wide diameter distribution beyond $180 \mathrm{~nm}$. The jet is extracted more violently from the Taylor cone resulting in filaments of larger diameters. molecules trapped in the lattice pores. When the initial degradation temperature is high, we observe a decrease in mass loss of nano-fibers of PA-6.

\subsection{Differential Scanning Calorimetry Analysis (DSC)}

The following figures represent the DSC thermograms 
recorded during the heating and cooling cycle of polyamide- 6

nano-fibers at $20^{\circ} \mathrm{C} / \mathrm{min}$ to $10^{\circ} \mathrm{C} / \mathrm{min}$.
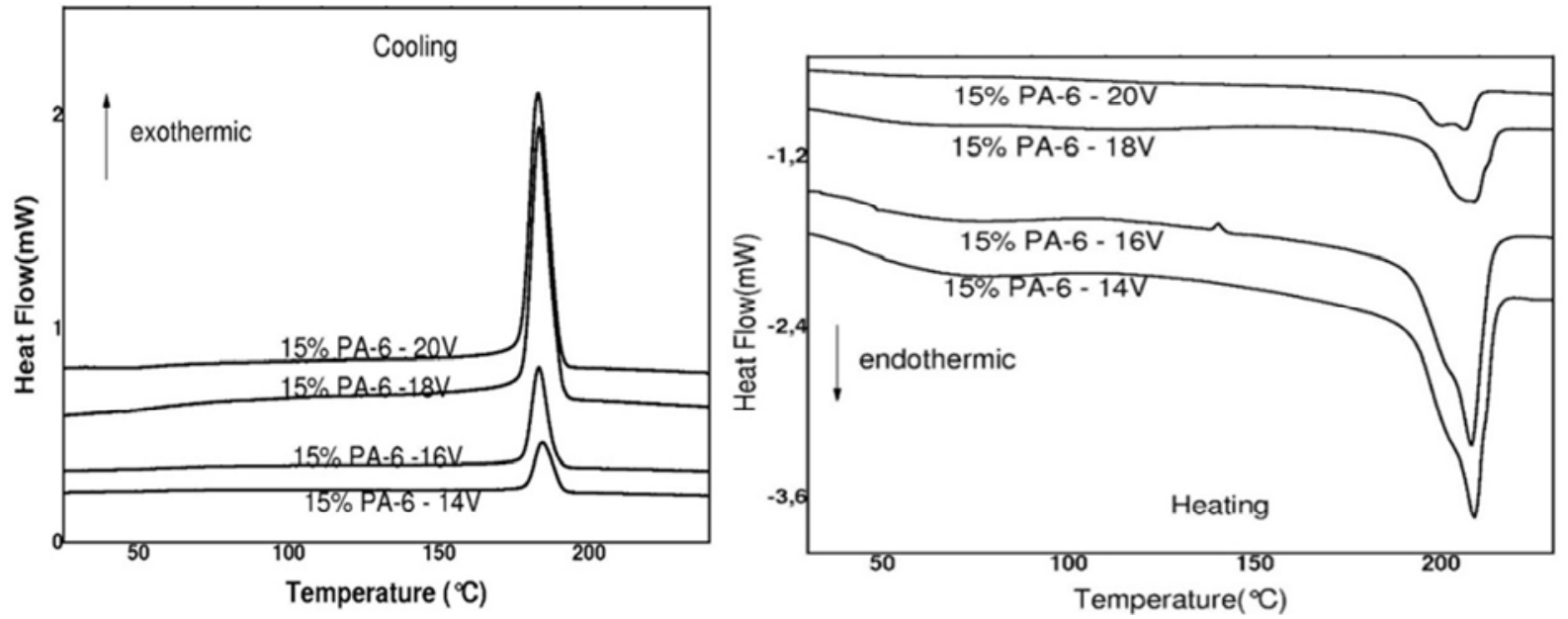

Figure 10. DSC thermograms of electro-spinning fibers from PA-6.

The thermograms obtained by DSC allowed us to measure the glass transition temperatures $\mathrm{Tg}$, melting temperature $\mathrm{T}_{\mathrm{f}}$ and crystallization temperature $\mathrm{Tc}$, as well as the enthalpies of melting $\Delta \mathrm{H}_{\mathrm{f}}$ and crystallization $\Delta \mathrm{H}_{\mathrm{c}}$ of our samples. The table below summarizes these results. It was used to determine the effects of electro-spinning fibers compared to the electrospinning process on polyamide- 6 . The DSC thermograms show that the maximum melting temperature $208^{\circ} \mathrm{C}$ and crystallization temperature $184^{\circ} \mathrm{C}$ are due to the re-generation of the hydrogen bond between the polyamide chains, on the other hand this tempera-tures decrease when the voltage used for the process increases. This corresponds to a degree of crystallinity of $32.59 \%$. The increase and the decrease of the voltage on the electrospinning also affect the melting enthalpy on the electros-spinning fibers of polyamide- 6 .

Table 7. Thermal properties of PA-6 nano-fibre films.

\begin{tabular}{|c|c|c|c|c|c|c|c|}
\hline Materials & Voltage $(k V)$ & $\mathbf{T}_{\mathrm{c}}\left({ }^{\circ} \mathrm{C}\right)$ & $\mathbf{T}_{\mathrm{f}}\left({ }^{\circ} \mathbf{C}\right)$ & $\mathrm{T}_{\mathrm{g}}\left({ }^{\circ} \mathrm{C}\right)$ & $\Delta \mathbf{H}_{\mathrm{c}}(\mathrm{J} / \mathrm{g})$ & $\Delta \mathbf{H}_{\mathrm{f}}(\mathrm{J} / \mathrm{g})$ & $\mathbf{X}_{\mathrm{c}}(\%)$ \\
\hline \multirow{4}{*}{$\begin{array}{l}\text { Films PA-6 } \\
\text { (nano-fiber) }\end{array}$} & $14 \mathrm{~V}$ & $184,29 \pm 2,2$ & $208,10 \pm 1,5$ & $59,0 \pm 0,1$ & $59,23 \pm 0,4$ & $54,46 \pm 0,9$ & $32,59 \pm 0,3$ \\
\hline & $16 \mathrm{~V}$ & $183,11 \pm 1,3$ & $208,24 \pm 2,2$ & $59,0 \pm 0,1$ & $51,44 \pm 0,1$ & $49,36 \pm 0,2$ & $28,09 \pm 0,2$ \\
\hline & $18 \mathrm{~V}$ & $183,24 \pm 2,2$ & $207,16 \pm 3,2$ & $58,0 \pm 0,2$ & $51,56 \pm 0,5$ & $45,23 \pm 0,5$ & $28,17 \pm 0,3$ \\
\hline & $20 \mathrm{~V}$ & $182,19 \pm 3,1$ & $206,88 \pm 2,6$ & $56,0 \pm 0,1$ & $61,26 \pm 0,2$ & $43,11 \pm 0,2$ & $31,65 \pm 0,1$ \\
\hline
\end{tabular}

\section{Conclusion}

A DoE based on the response surface method has been developed to determine the impact of key electrospinning parameters on the morphology of nano-fibers. By optimizing the electro-threading conditions of PA-6, we have been able to study the influence of these processes. The morphology of the fiber structures was studied by SEM. The results obtained were processed by the Image J software. These results show that the diameter as well as the morphology of the filaments depends on the voltage and voltage but also on the humidity level in the electro-spinning cabin. By varying these electrospinning parameters such as voltage and distance, we were able to observe different non-woven structures in terms of diameter and especially in terms of the presence, or not, of "pearl" structural defects. Regardless of how we varied these parameters, nano-fibrous size fibers are always obtained. Thus, we produced PA-6 nano-fibers with an average diameter that did not exceed $244 \mathrm{~nm}$, using a concentration of $15 \%$ by weight of PA-6. Fibres were produced without defects, with extremely small diameters and a large specific surface area. This will be used to manufacture photo deformable textiles. After spinning the flawless fibres, we can continue this study in the near future by adding a fire retardant active ingredient to the polyamide solution to improve the resistance of the fibres and their morphology.

\section{References}

[1] Song, Y.; Jiang, L.; Zhu, D., Super-hydrophobic surface of aligned polyacrylonitrile nanofibres. Angewandte Chemiz 2002, 114 (7), 1269-1271.

[2] Martin, C. R., Membrane-based synthesis of nanomaterials. Chem. Mater. 1996, (8), 1739-1746.

[3] Zhang, R., Synthetic nano-scale fibreus extracellular matrix. J. Biomed. Mater. Res. 1999, 46 (1), 60-72.

[4] Whitesides, G. M.; Grzybowski, B., Self-assembly at all scales. Science 2002, 295 (5564), 2418-2421.

[5] Liu, G.; Ding, J.; Saijo, K., Polystyrene-block-poly(2cinnamoylethyl methacrylate) Nanofibrs-Preparation, Characterization, and Liquid Crystalline Properties. Chem-eur. J. 1999, 5 (9), 2740-2749.

[6] Shah Hosseini, N. and N. Khenoussi, Structuring of electrospun nanofiber mats by $3 \mathrm{D}$ printing methods. 2017: p. 73-85. 
[7] Agarwal, S., J. H. Wendorff and A. Greiner, Use of electrospinning technique for biomedical applications. Polymer, 2008. 49 (26): p. 5603-5621.

[8] M. M. Demir, I Y1lgör, E Y1lgör, B Erman, "Electrospinning of polyurethane fibers", Polymer, 2002.43, 3303-3309.

[9] Fang, J., H. Niu, T. Lin and X. Wang, Applications of electrospun nanofibers. Chinese Science Bulletin, 2008. 53 (15): p. 2265

[10] Ng, R., R. Zang, K. K. Yang, N. Liu and S.-T. Yang, Threedimensional fibrous scaffolds with microstructures and nanotextures for tissue engineering. RSC Advances, 2012. 2 (27): p. 10110.

[11] Andrady, A. L., Science and technology of polymer nanofibers 2008: John Wiley \& Sons.

[12] Reneker, D. H., A. L. Yarin, H. Fong and S. Koombhongse, Bending instability of electrically charged liquid jets of polymer solutions in electrospinning. Journal of Applied physics, 2000. 87 (9): p. 4531-4547.
[13] Bhardwaj, N. and S. C. Kundu, Electrospinning: A fascinating fiber fabrication technique. Biotechnology Advances, 2010. 28 (3): p. $325-347$

[14] Khenoussi, N., L. Schacher and D. C. Adolphe, Nanofiber Production: Study and Development of Electrospinning Device. Experimental Techniques, 2012. 36 (2): p. 32-39.

[15] Nayak, R., R. Padhye, I. L. Kyratzis, Y. B. Truong and L. Arnold, Recent advances in nanofibre fabrication. Textile Research Journal, 2012. 82 (2): p. 129-147.

[16] Reneker, D. H. and A. L. Yarin, Electrospinning jets and polymer nanofibers. Polymer, 2008. 49 (10): p. 2387-2425.

[17] Doshi, J. and D. H. Reneker, Electrospinning process and applications of electrospun fibers. Journal of electrostatics, 1995. 35 (2-3): p. 151-160.

[18] Nazir A, Khenoussi N, Schacher L, Hussain T, Adolphe D, Hekmati AH. Using the Taguchi method to investigate the effect of different parameters on mean diameter and variation in PA-6 nanofibres produced by needleless electrospinning. RSC Adv 2015; 5 (94): 76892-76897. 